Fecha de recepción: junio 2020 Fecha de aceptación: agosto 2020 Versión final: septiembre 2020

\section{Design para o bem-estar: desafios enfrentados ao projetar para o estímulo a forças de caráter}

Leandro Miletto Tonetto ${ }^{(1)}$, Filipe Campelo Xavier

da Costa ${ }^{(2)}$, Roberta Rech Mandelli ${ }^{(3)}$, Bruno Lorenz $^{(4)}$ e Valentina Marques da Rosa ${ }^{(5)}$

Resumo: Forças de caráter são traços pessoais que indicam como as pessoas lidam com adversidades. Quando aplicam essas forças no cotidiano, seu bem-estar tende a ser desenvolvido, o que pode ser estimulado através do Design, segundo uma área emergente denominada Positive Design. Este artigo tem como objetivo investigar os desafios encontrados ao projetar para estimular forças de caráter. Sete profissionais graduados, todos estudantes de mestrado, foram preparados para desenvolver projetos na área. A pesquisa foi baseada na observação da prática desses designers durante suas atuações em workshops projetuais, que tiveram uma temática social como estímulo. Nessas ocasiões, uma mulher transgênera atuou como usuária do projeto e apontou oportunidades para o desenvolvimento de seu bem-estar. As atividades foram registradas em vídeo e acompanhadas por dois observadores. Os resultados indicam que os projetos desenvolvidos foram adequados para estimular o bem-estar da usuária e discutem os desafios encontrados durante o projeto.

Palavras chave: design positivo - bem-estar humano - filosofia do design.

[Resumos em espanhol e inglês nas páginas 165-166]

(1) Universidade do Vale do Rio dos Sinos, Brasil.

(2) Universidade do Vale do Rio dos Sinos, Brasil.

(3) Universidade do Vale do Rio dos Sinos, Brasil.

(4) Universidade do Vale do Rio dos Sinos, Brasil.

${ }^{(5)}$ Universidade Federal do Rio Grande do Sul, Brasil. 


\section{Introdução}

A área do design emocional se ocupa de projetos e pesquisas que tem como objetivo o estímulo emocional nas pessoas. Sua sempre foi a evocação ou prevenção de experiências efêmeras e circunstanciais. Um desafio emergente é como estimular experiências duradouras (Desmet \& Pohlmeyer, 2013).

No exercício de tentar responder a esta questão, a Psicologia Positiva surge como inspiração, contribuindo para o entendimento de como estimular o bem-estar duradouro. Seu foco é o ótimo funcionamento das pessoas, grupos e instituições (Seligman \& Csikszentmihalyi, 2000, 2001; Seligman, Stenn, Park, \& Peterson, 2005). Questões como potencial, motivação e realização humanas representam os principais tópicos de análise (Sheldon \& King, 2001). De forma complementar, os pesquisadores costumam estudar traços individuais positivos (Seligman, et al., 2005) que fundamentam os processos cognitivos e emocionais (Carr, 2007). Nessa direção, projetos de impacto social que partem de estímulo aos indivíduos podem beneficiar-se da teoria, estimulando o bem-estar subjetivo.

O bem-estar subjetivo pode ser entendido como a classificação que as pessoas fazem sobre a qualidade geral de suas vidas, em oposição ao bem-estar objetivo, que se refere a aspectos tangíveis, como ser seguro e bem nutrido. A dimensão subjetiva do bem-estar engloba a ideia de que a vida vale a pena ser vivida.

O conceito de virtude de Peterson e Seligman (2004) diz respeito ao que é considerado correto e moral para os seres humanos. Nessa direção, existem seis valores que parecem ser comuns a todas as culturas: sabedoria, coragem, humanidade, justiça, temperança e transcendência (Dahlsgaard, Peterson, \& Seligman, 2005). Estimulá-los pode contribuir para a formação de uma sociedade mais saudável para todos.

Virtudes são subdivididas em forças de caráter, que por sua vez são traços positivos de personalidade, como liderança ou criatividade, e mostram "como um individual lida com adversidades" (Peterson \& Seligman, 2004, p. 17, tradução nossa). A teoria defende que se um indivíduo utilizar suas principais forças de caráter todos os dias, seu nível de bemestar subjetivo tende a aumentar.

A Psicologia Positiva ajudou a moldar uma das abordagens atuais de design para o bemestar, conhecida como Positive Design (Desmet \& Pohlmeyer, 2013). No entanto, pouco se discutiu sobre esta. A área de estudos do Positive Design necessita de aprofundamento teórico e desenvolvimento metodológico. Consequentemente, designers, estudantes e educadores podem encontrar desafios desconhecidos em exercícios projetuais que se utilizam desta abordagem. Sendo assim, este artigo tem como objetivo investigar os desafios enfrentados ao projetar para estimular forças de caráter, de acordo com o modelo teórico do Positive Design (Desmet \& Pohlmeyer, 2013).

Sete designers profissionais, que também são estudantes de mestrado que integraram uma disciplina sobre experiência do usuário, foram especificamente treinados para utilizar essa abordagem. Eles aplicaram esse conhecimento em workshops de design extracurriculares e sua prática foi observada. É importante destacar que o foco do presente estudo não é o resultado final destes projetos; e sim os desafios encontrados e as estratégias utilizadas para superá-los. 
A temática do workshop consistia em projetar para o bem-estar de uma pessoa, motivando-a a utilizar suas forças de caráter. A pessoa (referida como Jade neste artigo) era uma mulher transgênera de 25 anos de idade, que atua na área de tecnologia da informação e relata algumas dificuldades de interação em contextos sociais. Como os designers receberam um briefing baseado nas suas necessidades, supondo que estivessem trabalhando com e para ela, Jade agiu como usuária durante o exercício de projeto.

Nas próximas seções, explora-se os principais conceitos acerca do Positive Design (2), descreve-se seus métodos (3), explora-se os resultados (4) e, finalmente, apresenta-se a discussão e as conclusões (5).

\section{Fundamentos do Positive Design}

Desmet e Pohlmeyer (2013) propuseram um constructo para o Positive Design que é baseado em três pilares: (a) estimular experiências de afeto positivo (e reduzir as de afeto negativo); (b) design para significado pessoal; (c) design para virtudes; já que comportamentos relacionados a elas tendem a contribuir para o bem-estar humano.

O design para o prazer relaciona o bem-estar subjetivo com a soma de momentos agradáveis que alguém tem ao longo da vida. Ele se foca em situações que acontecem "aqui" e "agora", como relaxar e se divertir. O design pode ser a própria fonte do prazer ou estimulá-lo, além de ajudar a reduzir sentimentos negativos em relação a diferentes circunstâncias da vida.

O significado pessoal se refere aos objetivos de curto e longo prazo que uma pessoa possa ter, como correr uma maratona ou ser aprovado em uma prova. Ele também se refere às conquistas significativas da vida, ou aos sentimentos de avanço em direção a um futuro desejado. O design pode ajudar uma pessoa a se aproximarem de seus objetivos ou até mesmo a lembrar-se de triunfos passados.

Virtudes são valores humanos que revelam a existência de um senso de excelência que leva a uma vida virtuosa. Esses valores normalmente são divididos em forças de caráter:

[...] as virtudes são as características centrais valorizadas pelos filósofos morais e pensadores religiosos: sabedoria, coragem, humanidade, justiça, temperança e transcendência. Forças de caráter são processos ou mecanismos psicológicos mais específicos que definem estas virtudes. Para transmitir a multidimensionalidade do bom caráter, nos referimos aos seus componentes como forças de caráter (...). Não há razão para os educadores e profissionais se absterem de avaliar um único componente de bom caráter -como bondade, esperança ou trabalho em equipe-, mas seria um erro tratar desse único componente avaliado de uma maneira particular como sendo a totalidade do entendimento do que configura um bom caráter. Indivíduos podem ser muito gentis ou muito esperançosos e mesmo assim não terem outros componentes de bom caráter (Park \& Peterson, 2009, p. 3, tradução nossa). 
Peterson e Seligman (2004) classificam seis virtudes (sabedoria, coragem, humanidade, transcendência, justiça, e temperança) e as organizam em 24 forças de caráter amplamente valorizadas.

A abordagem também inclui cinco elementos de design: (a) é orientado a possibilidades, uma vez que o foco "não é a redução de deficiências, mas o estímulo da excelência" (p. 11, tradução nossa); (b) equilíbrio, o que significa que nem sempre os três pilares serão usados uniformemente, mas não se deve ir contra um deles; (c) o projeto deve apresentar ajuste pessoal, movendo-se contra a ideia de "um tamanho único que serve a todos" (p.12, tradução nossa); (d) permite o envolvimento ativo do usuário; e (e) deve ter o potencial de apresentar impacto de longo prazo.

Esse constructo é complementado por outros pesquisadores, como Sääksjärvi e Hellén (2013), que apresentam três proposições de design neste contexto. O design deve (a) estimular relações sociais e o sentimento de pertença, (b) ajudar a atribuir significado à vida, e (c) tornar as pessoas ativamente envolvidas com artefatos, ao invés de se concentrar na interação passiva. Portanto, não se foca apenas no produto, mas também nas atividades envolvidas em seu uso.

O Positive Design está em estágio inicial de desenvolvimento. Seus fundamentos são encontrados na pesquisa de Desmet e Pohlmeyer (2013), que por sua vez é baseada em autores da psicologia, como Peterson e Seligman (2004). Existem algumas proposições de como aplicá-lo, mas a descrição sobre como projetar usando a abordagem ainda é superficial, razão pela qual esta pesquisa se concentra em desafios encontrados por designers ao projetar para o estímulo de forças de caráter.

\section{Métodos}

Nesta pesquisa foi utilizado um método exploratório. Profissionais que também eram estudantes de mestrado em design foram treinados para projetar para forças de caráter e participaram de um workshop. Sendo assim, as próximas seções caracterizam os participantes da pesquisa (3.1), o protocolo do workshop (3.2), o desenvolvimento do workshop (3.3) e como os dados foram coletados e analisados (3.4).

\subsection{Participantes e seu treinamento}

Sete designers ( 2 homens, 5 mulheres; idade média 35.9 anos; média de 9.9 anos de experiência) foram treinados em uma disciplina de mestrado e aprenderam teorias e práticas na área do design emocional. O treinamento ocorreu ao longo de 14 encontros de três horas cada e um workshop final de quatro horas.

A seleção de teorias e abordagens do treinamento tinha como pretensão partir de um ensino básico sobre experiência (tópico geral), experiência emocional e experiência do produto (Desmet \& Hekkert, 2007; Tonetto \& Costa, 2011; Carú \& Cova, 2008; Csikszentmihalyi, 1997). Depois de conhecer os fundamentos da relação entre design e experiência 
emocional, o conteúdo passou de abordagens mais simples para teorias mais complexas de design para as emoções do usuário (Jordan, 2000; Norman, 2012; Demir, Desmet, \& Hekkert, 2009; Ozkaramanli \& Desmet, 2012, nesta ordem). Um módulo final abordou contribuições duradouras do design para a vida humana, com foco no design para o humor e bem-estar (Desmet \& Pohlmeyer, 2013; Desmet, 2015).

\subsection{Protocolo do workshop: projetando para virtudes por meio de forças de caráter}

As experiências de Demir, Ozkaramanli e Desmet (2010) inspiraram o planejamento do workshop. O constructo do Positive Design introduzido por Desmet e Pohlmeyer (2013) e as proposições de Sääksjärvi e Hellén (2013) ajudaram a projetar uma estrutura que correspondesse aos objetivos da pesquisa, que foi baseada em um verdadeiro desafio de design. O workshop envolveu seis etapas. Cada etapa é descrita nas próximas seções (de 3.2.1 até 3.2.6) e brevemente representada na tabela 1 (subcapítulo 3.3).

\subsubsection{Etapa 1: definição de um usuário ou grupo de usuários}

A primeira etapa requer a definição de um usuário, ou um grupo de usuários, com uma clara demanda para melhorar o bem-estar subjetivo. Apesar do Positive Design ser voltado para possibilidades, e não para dificuldades a serem superadas (Desmet \& Pohlmeyer, 2013), uma demanda clara pode ajudar os iniciantes a enfrentarem o desafio de melhorar o bem-estar subjetivo de alguém.

Esta etapa depende de usuários reais para tornar o desafio mais realista. Ter um usuário que possa se engajar no workshop pode ajudar os designers a ter empatia para com ele, e não fantasiar sobre quais são seus gatilhos para o bem-estar e como as forças de caráter fazem sentido para os outros.

\subsubsection{Etapa 2: identificando as forças de caráter}

A segunda etapa consiste em identificar as principais forças de caráter do(s) usuário(s), uma vez que elas consistem em informações de projeto para o bem-estar (Desmet \& Pohlmeyer, 2013). Existem alguns questionários disponíveis para avaliá-las, mas sugere-se o uso do VIA Character Strengths (http://viacharacter.org/www/Character-Strengths-Survey). Desenvolvido pelo Dr. Seligman, este questionário mede as forças de caráter de um indivíduo e deve ser respondido pelo usuário antes do dia do workshop. Após completálo, tem-se um relatório online no qual as 24 forças de caráter são ranqueadas de acordo com o nível em que estão desenvolvidas pelo respondente em questão, sendo que as principais forças de caráter de alguém são as que melhor forem classificadas.

Se possível, nesta abordagem, uma ou mais dessas principais forças devem ser relacionadas à demanda relatada pelos usuários. Por exemplo, se o usuário relata a necessidade de melhorar suas interações sociais, essa demanda pode estar relacionada a uma força de caráter como liderança. Dessa forma, o projeto pode estimular o contato social em um contexto no qual o usuário possa usar habilidades para conduzir grupos, por exemplo. 


\subsubsection{Etapa 3: perfil de projeto}

A terceira etapa diz respeito ao "perfil de projeto". Os produtos não são comumente vistos como fontes únicas de bem-estar subjetivo (Sääksjärvi \& Hellén, 2013), de modo que os projetos devem evitar que seu foco esteja unicamente em artefatos materiais. O projeto deve contemplar não apenas o produto, mas também as atividades que estão envolvidas em seu uso.

Os designers devem aplicar os três pilares do constructo proposto por Desmet e Pohlmeyer (2013), que envolvem: design para virtudes humanas, para estímulo de experiências de afeto positivo e minimização do afeto negativo, e para o significado pessoal. Também é solicitado que os projetistas utilizem os cinco elementos do constructo: orientado a possibilidades, equilíbrio, adequação pessoal, envolvimento ativo do usuário e impacto de longo prazo.

\subsubsection{Etapa 4: desenvolvimento do projeto}

Os designers são livres para usar qualquer tipo de ferramenta ou método de projeto durante o workshop. Eles são convidados a desenvolver seus projetos em um nível conceitual e representá-lo através de esboços ou qualquer outra forma de representação visual. Esta quarta etapa foi inspirada na proposta de Demir, Ozkaramanli e Desmet (2010).

\subsubsection{Etapas 5 e 6: avaliação do projeto}

A quinta e sexta etapas consistem na avaliação das propostas de projeto pelo usuário e pelos especialistas (neste caso, dois professores pesquisadores). Essas etapas de avaliação permitem que seja feita uma avaliação de diferentes perspectivas sobre o potencial do projeto em contemplar todos os pilares do constructo do Positive Design. Como nesta pesquisa havia um único usuário no workshop, as avaliações podem ser consideradas completas e abrangentes.

$\mathrm{Na}$ quinta etapa, a representação do projeto é apresentada ao usuário, e os argumentos por trás das decisões são discutidos. O usuário avalia cada design, sugerindo melhorias.

Já na sexta etapa é o especialista que avalia cada design, com base nos três pilares e cinco elementos do constructo do Positive Design. Aqui o processo é o mesmo que o empregado na etapa 5, mas a argumentação se utiliza de termos e conceitos teóricos, e os designers recebem um feedback estruturado.

\subsection{Desenvolvimento do workshop}

Na tabela 1, as etapas utilizadas nesta abordagem são apresentadas na coluna da esquerda, enquanto o seu uso nesta pesquisa está descrito na coluna da direita. A duração das atividades foi baseada na experiência de projeto desta pesquisa. A pessoa que atuou como usuária é referida como "usuário" nas tabelas 1 e 2, fazendo referência à linguagem encontrada em pesquisas com usuários e estudos de projeto de experiência. 
Tabela 1. Abordagem de design para virtudes (esquerda) e sua aplicação no workshop (direita)

\begin{tabular}{|c|c|}
\hline Etapas & Descrição \\
\hline $\begin{array}{l}\text { (1) Definir um usuário, ou um } \\
\text { grupo de usuários, com uma } \\
\text { demanda clara para promoção } \\
\text { de bem-estar subjetivo. }\end{array}$ & $\begin{array}{l}\text { Antes do workshop, selecionou-se a pessoa (Jade) com } \\
\text { uma demanda clara para a melhor de seu bem-estar } \\
\text { subjetivo. Ela é uma mulher transgênera, que trabalha na } \\
\text { área de tecnologia da informação e que relatou problemas } \\
\text { em interações sociais. }\end{array}$ \\
\hline $\begin{array}{l}\text { (2) Identificar suas principais } \\
\text { forças de caráter e relacioná- } \\
\text { las com pelo menos uma das } \\
\text { demandas relatadas. }\end{array}$ & $\begin{array}{l}\text { Os pesquisadores tiveram um encontro com Jade } \\
\text { para apresentar os objetivos do projeto. Foi solicitado } \\
\text { que ela respondesse ao VIA Character Strengths } \\
\text { depois do encontro. O relatório gerado permitiu que os } \\
\text { pesquisadores pudessem entender suas forças de caráter } \\
\text { e assim planejar como o workshop seria conduzido. }\end{array}$ \\
\hline (3) Gerar um perfil de projeto. & $\begin{array}{l}\text { Essa foi a primeira etapa conduzida no dia do workshop. } \\
\text { A atividade iniciou com uma fala de Jade sobre o seu } \\
\text { contexto social ( } 30 \text { min). Depois, os pesquisadores } \\
\text { apresentaram suas } 5 \text { principais forças de caráter, } \\
\text { baseadas no relatório do VIA ( } 15 \text { min) (figura 4), e o briefing } \\
\text { do workshop ( } 15 \text { min) (figura } 5) \text {. } \\
\text { Os designers eram livres para usar quaisquer técnicas e } \\
\text { ferramentas para o desenvolvimento do perfil de projeto } \\
\text { (60 min). Os pesquisadores e a Jade estavam disponíveis } \\
\text { para responder dúvidas, e deveriam validar as ideias dos } \\
\text { designers antes que estes iniciassem a quarta etapa. }\end{array}$ \\
\hline
\end{tabular}

(4) Projetar o artefato de acordo Os designers deveriam desenvolver seus projetos em um com o perfil de projeto. nível conceitual, incluindo o uso livre de ferramentas de design, e depois representá-los por meio de um sketch ou outra ferramenta de representação visual (60 min).

(5) Avaliação do potencial do projeto no estímulo do bemestar - perspectiva do usuário.
Os resultados foram apresentados para Jade, e os argumentos por trás dos mesmos foram discutidos com ela (30 min). Ela avaliou cada um dos projetos, sugerindo melhorias.
(6) Avaliação do projeto de acordo com o constructo do Positive Design.
Os especialistas avaliaram o projeto, fornecendo feedback aos designers (30 min). 


\begin{tabular}{|c|c|c|}
\hline forcas de caráter & descriçāo & exemplos \\
\hline ด1. CRIATIVIDADE & 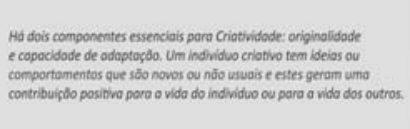 & 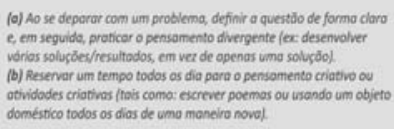 \\
\hline 82. HONESTIDADE & 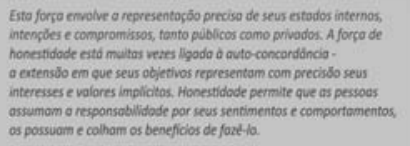 & 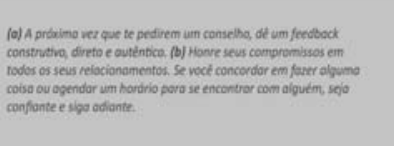 \\
\hline 93. HUMOR & 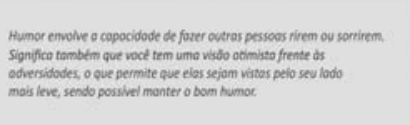 & 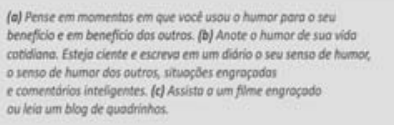 \\
\hline 84. BONDADE & 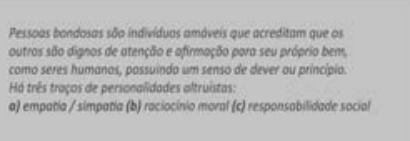 & 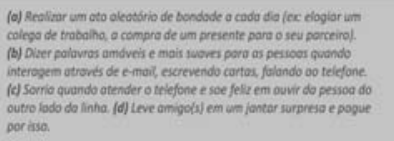 \\
\hline $\begin{array}{l}\text { 05. APRECIACAOO } \\
\text { DA BELEZA E DA } \\
\text { EXCELENCIA }\end{array}$ & 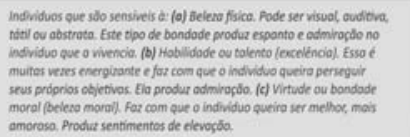 & 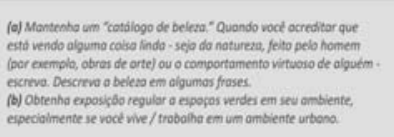 \\
\hline
\end{tabular}

Figura 1. As cinco principais forças de caráter de Jade.

\subsection{Coleta e análise de dados}

Esta pesquisa utilizou um método exploratório, analisando a prática de 7 designers. $\mathrm{O}$ objetivo do estudo foi investigar os desafios enfrentados ao projetar para estimular forças de caráter. Portanto, mesmo que a workshop tenha gerado resultados interessantes, os resultados dos projetos desenvolvidos pelos participantes não são o foco neste artigo, razão pela qual eles são descritos brevemente na próxima seção (Exemplo de solução de design), a análise se aprofunda na aplicação do workshop e nos principais desafios encontrados durante o processo de projeto.

No dia do workshop, os designers foram divididos em dois grupos. Dois pesquisadores e dois assistentes de pesquisa observaram e supervisionaram os grupos. Os grupos receberam o mesmo briefing e trabalharam no projeto, conforme descrito na subseção anterior. O processo de cada grupo foi observado por um dos pesquisadores, que registrou os principais conteúdos em um diário de campo, além do registro em vídeo do processo, para permitir a exploração futura dos materiais.

A análise efetuada pode ser descrita como uma Análise Temática. Os observadores agruparam os resultados a partir das etapas do workshop, identificando os desafios encon- 
trados pelos designers e também as estratégias empregadas para sua superação. Em dois encontros de aproximadamente duas horas cada, os temas (dificuldades e estratégias de superação) foram discutidos e agrupados por conteúdo.

\section{Resultados}

Esta seção apresenta brevemente os resultados de um grupo, com o objetivo de ilustrar e facilitar a compreensão dos sucessos e dificuldades encontradas durante o workshop. Antes de apresentar os resultados do workshop, é importante destacar alguns pontos que surgiram na fala de Jade. Ela é uma profissional que trabalha na área de tecnologia da informação (TI) e ministra diversas palestras ao redor do Brasil. Ela é constantemente convidada a participar de eventos em áreas relacionadas à TI e à inclusão de mulheres nesse mercado. Ela ministra cursos para minorias (não apenas para mulheres transgêneras), com o objetivo de capacitá-las para ter sucesso na área de TI. Temáticas como inclusão, ativismo e feminismo foram recorrentes em sua fala de 30 minutos.

Além de serem temas que representam suas paixões de vida, trabalhar com e para as pessoas também foi mencionado por Jade como motivador. Por outro lado, suas relações sociais, não apenas no trabalho, foram mencionadas como oportunidades para melhorar sua vida. Ela relatou que atividades simples do dia a dia, como passear com seus cachorros, se tornam exaustivas, já que Jade é alvo constante de agressões por parte de pessoas desconhecidas. Ela também é alvo de frequentes ataques cibernéticos em redes sociais como Facebook e Instagram. Mesmo enfrentando dificuldades, ela mencionou estar muito motivada em trabalhar para mudar esta realidade.

Conforme indicado e descrito na figura 4, os resultados de seu teste VIA Character Strengths indicaram cinco principais forças de caráter, que são: criatividade, honestidade, humor, bondade e apreciação da beleza e excelência.

\subsection{Exemplo de solução de design}

Ao projetar por meio das lentes do Positive Design, um dos grupos explorou a temática do ativismo, fazendo de Jade uma agente de transformação social, reforçando atividades de alto significado pessoal. A ideia foi baseada no conceito de branding pessoal -pessoas que transformam sua imagem própria e suas carreiras em marcas- conectando as habilidades e desejos de Jade em empoderar minorias por meio do ensino de tecnologia, disseminando respeito e diversidade. A solução proposta envolveu a identidade visual de Jade e de plataformas e serviços digitais que a permitiam comunicar-se com seus alunos, além de ensiná-los. É o projeto de um sistema, que utiliza várias plataformas existentes para entregar um serviço.

De acordo com os designers, a solução apresentada se relacionava com algumas das forças de caráter de Jade, sendo elas: criatividade, considerando que a plataforma permite que ela desenvolva vários serviços autorais; honestidade, já que a marca pessoal exige 
autenticidade de Jane; humor, pois seus serviços ofereceriam uma visão positiva sobre a diversidade; e, finalmente, bondade, pois eles estariam servindo uma causa relacionada à inclusão social.

O grupo explorou de forma satisfatória os aspectos teóricos do Positive Design durante a apresentação final. A solução proposta envolve as virtudes do usuário (através das forças de caráter), o prazer (que viria das relações pessoais que ela construiria ao propor atividades de ensino) e o significado pessoal (espalhando "sementes de empoderamento e o respeito pela diversidade"). O projeto é voltado para possibilidades, pois explora diversas formas de promover a autoafirmação; tem equilíbrio porque aplica os três pilares do constructo; tem ajuste pessoal, estando de acordo com a personalidade altruísta de Jade; pressupõe o envolvimento ativo da usuária, já que ela seria uma agente de transformação; e tem um impacto duradouro, permitindo a satisfação da usuária em compartilhar conhecimento e empoderamento através de suas ações, além de poder ver os resultados de suas ações.

Depois de conhecer um exemplo dos processos e resultados do workshop, o leitor encontra, na próxima seção, os resultados reais da pesquisa: os sucessos e as dificuldades que os designers encontraram no processo de projeto.

\subsection{Resultados: sucessos e dificuldades encontrados}

Os resultados da pesquisa foram divididos de acordo com dois momentos do workshop: o antes e o depois da validação do conceito de projeto pela Jade, o que ocorreu entre as etapas 3 e 4, descritas na tabela 1. Os resultados são apresentados seguindo o cronograma do workshop. Dessa forma, algumas dificuldades, como o uso de bases teóricas, aparecem mais de uma vez em diferentes etapas do processo. Eles são apresentados na tabela $2 \mathrm{e}$ discutidos a seguir.

Tabela 2. Resultados antes e depois da avaliação da usuária

\begin{tabular}{ll}
\hline Etapa & Resultado \\
\hline Antes da validação & a) $\begin{array}{l}\text { Ligação imediata percebida pelos designers entre a fala da usuária } \\
\text { e o briefing de projeto. }\end{array}$ \\
\cline { 2 - 2 } & $\begin{array}{l}\text { A interação designer-usuária estimulou a discussão de aspectos } \\
\text { que não estavam relacionados ao briefing, atrasando o início do } \\
\text { processo sobre a temática de projeto. }\end{array}$ \\
\hline c) $\begin{array}{l}\text { A geração de ideias baseada nas forças de caráter facilitou a } \\
\text { adesão ao briefing. }\end{array}$ & $\begin{array}{l}\text { A temática de design, baseada em uma perspectiva pessoal, } \\
\text { levou alguns dos designers a confundirem suas próprias } \\
\text { experiências e gatilhos para o bem-estar com as da usuária. }\end{array}$ \\
\hline
\end{tabular}




\begin{tabular}{|c|c|c|}
\hline & e) & $\begin{array}{l}\text { Alguns dos cinco elementos propostos por Desmet e Pohlmeyer } \\
\text { (2013) são mais difíceis de serem utilizados nos estágios iniciais } \\
\text { do processo de projeto, tornando difícil para os iniciantes avaliar } \\
\text { quão adequadas são suas ideias para aplicar a abordagem. }\end{array}$ \\
\hline & f) & $\begin{array}{l}\text { A geração de ideias costumava começar antes que os designers } \\
\text { tivessem certeza de como suas ideias se encaixavam nos cinco } \\
\text { elementos do constructo do Positive Design. }\end{array}$ \\
\hline & g) & $\begin{array}{l}\text { Baseado nos resultados da geração de ideias, os designers } \\
\text { buscaram razões para continuar projetando para forças de caráter } \\
\text { específicas. }\end{array}$ \\
\hline & h) & $\begin{array}{l}\text { O processo não é linear: a geração de ideias é estimulada pela } \\
\text { validação que os designers buscam nos aspectos teóricos do } \\
\text { Positive Design. }\end{array}$ \\
\hline & i) & $\begin{array}{l}\text { Os designers mantêm o foco na conversa com a usuária, } \\
\text { abstendo-se de procurar outras formas de responder ao briefing } \\
\text { de projeto. }\end{array}$ \\
\hline & j) & $\begin{array}{l}\text { O caráter abstrato da tarefa resultou em dificuldades na geração } \\
\text { de soluções concretas em uma perspectiva de projeto. }\end{array}$ \\
\hline & k) & $\begin{array}{l}\text { Os designers encontraram dificuldades no desenvolvimento de um } \\
\text { perfil de projeto baseado em ideias fundamentadas nos aspectos } \\
\text { teóricos da tarefa. Algumas não eram relacionados ao constructo } \\
\text { do Positive Design. }\end{array}$ \\
\hline & l) & $\begin{array}{l}\text { Notou-se dificuldades na compreensão do que deveria ser a } \\
\text { entrega de projeto (produto, serviço, sistema), uma vez que os } \\
\text { designers tentaram usar o design para o bem-estar como uma } \\
\text { área de aplicação, ao invés de um campo de conhecimento. }\end{array}$ \\
\hline & m) & $\begin{array}{l}\text { A presença da usuária durante o workshop facilitou o ajuste } \\
\text { pessoal dos projetos. }\end{array}$ \\
\hline Depois da validação & n) & $\begin{array}{l}\text { A validação do processo com a usuária facilitou o } \\
\text { desenvolvimento do perfil de projeto, que ainda não estava } \\
\text { completamente finalizado naquele momento. }\end{array}$ \\
\hline & 0) & $\begin{array}{l}\text { Os designers sentiram-se livres para utilizar apenas algumas das } \\
\text { forças de caráter da usuária depois da validação, libertando- } \\
\text { se da ideia de ter que usar todos as cinco forças de caráter } \\
\text { apresentadas no briefing. }\end{array}$ \\
\hline & p) & $\begin{array}{l}\text { De acordo com a usuária e ambos os pesquisadores, os } \\
\text { designers foram capazes de projetar de acordo com os três } \\
\text { pilares do Positive Design (virtudes, prazer e significado pessoal). }\end{array}$ \\
\hline
\end{tabular}


q) De acordo com a usuária e ambos os pesquisadores, os designers foram capazes de projetar de acordo com os cinco elementos do Positive Design: orientado a possibilidades, equilíbrio, adequação pessoal, envolvimento ativo do usuário e impacto de longo prazo.

r) A duração do workshop dificultou a apresentação de boas representações dos conceitos de design.

Os designers perceberam uma ligação imediata entre a fala de Jade e o briefing do workshop (a). A descrição de seu cotidiano e as repetidas referências a temáticas como ativismo e feminismo auxiliaram no desenvolvimento de um perfil de projeto. A visão de Jade como uma agente de mudança social foi uma conclusão natural de uma interação real entre ela e os designers.

Por outro lado, em alguns momentos a interação com Jade estimulou a discussão de aspectos que não estavam relacionados ao briefing (b). Embora a conversa apoiasse ideias fundamentadas, os aspectos teóricos do briefing foram postos em segundo plano, como um terceiro elemento que interferiu negativamente no fluxo de ideias entre os designers e a Jade. Essa característica teórica do briefing atrasou o início do desenvolvimento do projeto.

A geração de ideias baseada nas forças de caráter facilitou a adesão ao briefing (c) na medida em que simplificou a identificação de ligações entre contextos da vida real e forças de caráter: "Eu acho [...] que ela estimula a criatividade dela por meio das aulas que ela dá, talvez tenha essa questão muito forte. [...] o objetivo é que a gente projete para força de caráter".

Apesar das referências às forças de caráter terem facilitado o processo, esse protagonismo no uso das informações humanas em tempo real dificultou o foco na tarefa de projeto. Essa confusão aconteceu quando o briefing levou alguns designers a se identificarem com Jade e a confundirem seus próprios gatilhos com os dela (d): "Como a gente estimularia a criatividade por meio de um ambiente?", comentou uma das designers, que tem experiência em design de interiores.

Como o briefing do workshop foi criado a partir de uma base teórica forte, os profissionais foram desafiados a pensar por uma perspectiva diferente. Dessa forma, foi possível notar que alguns dos cinco elementos propostos por Desmet e Pohlmeyer (2013) são mais difíceis de identificar nos estágios iniciais do processo de projeto (e), dificultando o processo dos iniciantes de avaliar seus próprios projetos em relação à aplicação da teoria. Também ficou evidente que o equilíbrio e o impacto de longo prazo foram os elementos mais negligenciados pelos profissionais antes da validação com a Jade, embora eles tenham sido incluídos em etapas posteriores do processo.

A dificuldade em considerar todos os elementos do constructo estimulou os profissionais a iniciarem o processo criativo. A geração de ideias costumava iniciar antes que os designers tivessem certeza de quão bem suas ideias se enquadravam nos cinco elementos do constructo do Positive Design (f), e apenas quando exploravam ideias eles eram capazes 
de relacionar os aspectos teóricos do briefing e as forças de caráter de Jade: "Eu acho que a gente está se amarrando muito nessa primeira ideia [...]. Vamos fazer um brainstorm mais amplo. Trazer todas ideias loucas, por mais idiotas que ela sejam, pra gente tentar ver da onde a gente pode partir depois".

Somente após esse processo, com base nos resultados da geração de ideias, os profissionais buscaram motivos para continuar trabalhando em pontos específicos das forças de caráter (g). Diferentemente dos desafios comuns aos processos de design de produto que eles estão acostumados a enfrentar, esse foi um processo não-linear com inspirações e desafios teóricos" (h).

Mesmo que o processo não tenha sido pautado por um roteiro metodológico, como as abordagens de design costumam fazer, alguns grupos de designers guiaram-se pela fala da usuária, abstendo-se de procurar outras formas de responder ao briefing (i). Alguns designers só trabalharam em ideias geradas a partir de insumos trazidos pela fala de Jade, como por exemplo, criando conteúdos sobre o "mundo transgênero", sem olhar para outros aspectos de sua vida que poderiam ter sido interessantes em uma perspectiva de design.

A natureza abstrata da temática de projeto resultou em dificuldades para gerar soluções de design concretas (j): "Agora, como é que a gente projeta algo pra isso [forças de caráter], sabe? Porque eu achei bárbaro essas ideias, mas...”. Projetar um perfil de projeto baseado em aspectos teóricos foi desafiador para alguns dos designers, a ponto de algumas de suas ideias não estarem relacionadas ao constructo do Positive Design (k).

De forma complementar, o aspecto abstrato do briefing, que não focava em um produto específico, também trouxe dificuldades no entendimento do que deveria configurar a solução final (produto, serviço ou sistema) (l). No início, os designers tentaram usar o design para o bem-estar como uma área de aplicação, ao invés de um campo de conhecimento. Esse processo foi facilitado pela presença e interação com a usuária no dia do workshop, uma vez que o ajuste pessoal pareceu ser o elemento principal do constructo, de forma que deveria guiar a escolha da solução final de projeto $(\mathrm{m})$.

Após a Jade validar os conceitos de projeto, os profissionais foram capazes de superar a maior parte das dificuldades e os desafios teóricos ficaram em segundo plano. Até esse momento, o perfil de projeto não estava totalmente definido (n). Os designers se livraram da necessidade auto-imposta de usar todas cinco forças de caráter (o), percebendo que estas deveriam ser apenas guias para facilitar a integração de virtudes ao projeto. Dessa forma, eles foram capazes de formular argumentos para justificar sua escolha de focar o projeto em algumas das forças apresentadas, o que pode ser visto neste fragmento de um dos grupos:

[Nosso projeto contempla] a criatividade, por meio da criação de conteúdos e dos materiais de ensinos dos cursos; a honestidade, tendo em vista que o serviço prioriza a essência da usuária e sobre o que ela acredita [ativismo e feminismo]; o humor, pois será possível que ela transmita alegria pelos canais de relacionamento criados; a bondade, ao ajudar seus alunos a transformar suas próprias realidades; e, finalmente, a apreciação da beleza e da excelência, pois o ambiente versátil estimularia a usuária a criar espaços que atendam a seus objetivos éticos e estéticos. 
No final, de acordo com Jade e as avaliações dos pesquisadores, os designers conseguiram desenvolver seus projetos fundamentados nos três pilares do Positive Design (virtudes, prazer e significado pessoal) (p). Um fragmento da explicação dos designers de um dos grupos pode ser visto como um exemplo de consistência teórica em sua apresentação final, quando os mesmos resumiram como a solução contemplava às questões do briefing: "A virtude é expressa na relação do projeto com as forças de caráter da usuária; o prazer, identificado nas relações pessoais que a Jade teria ao se propor a uma prática de ensino; e o significado pessoal, que diz respeito a espalhar sementes de empoderamento e respeito à diversidade".

Os designers também foram capazes de mostrar um uso consistente dos cinco elementos do Positive Design: orientação a possibilidades, equilíbrio, ajuste pessoal, envolvimento ativo do usuário e impacto de longo prazo (q), fornecendo o mesmo tipo de explicação fundamentada em uma apresentação final. Foi possível notar que a decisão de incluir no workshop uma apresentação na qual os grupos teriam que defender seus projetos, explicando como os mesmos respondiam às questões teóricas, pareceu desafiá-los a construir projetos que fossem bem fundamentados e a dominar os conceitos por trás deles.

Apesar da boa adequação teórica, a representação visual dos projetos poderia ter sido melhor trabalhada. A curta duração do workshop dificultou a apresentação de boas representações dos conceitos de design (r).

\section{Discussão e Conclusão}

Embora os designers tenham tido dificuldades em identificar como usar todos os cinco elementos do constructo de Desmet e Pohlmeyer (2013) nos estágios iniciais do workshop, especialmente o equilíbrio e o impacto de longo prazo, todos eles foram aplicados e os designers compreenderam sua importância após a validação dos conceitos de projeto pela Jade. O constructo dos autores foi central para o workshop, e as proposições de Sääksjärvi e Hellén (2013) foram entendidas apenas como uma forma de reforçá-lo.

Os elementos de equilíbrio e o impacto a longo prazo só fizeram sentido para os designers quando discutidos a partir de conceitos de design já formulados. Os outros elementos (orientação a possibilidades, ajuste pessoal e envolvimento ativo do usuário) foram vistos como insumos para escolher as temáticas de projeto e definir seu foco, enquanto os dois mencionados anteriormente foram considerados quando o conceito estava sendo finalizado.

A participação de uma pessoa real como usuária foi uma grande contribuição para o processo de projeto e também permitiu uma validação em tempo real dos conceitos gerados em uma perspectiva de longo prazo. Um fragmento da avaliação final de Jade exemplifica o tipo de feedback dado pelos usuários:

Eu quero dizer que eu to bem feliz, bem feliz mesmo de ter participado [...] de ter conseguido passar pra vocês um pouquinho de mim [...] um pouquinho não, acho que um montão [...] Realmente, vocês me deram um up fantástico 
[com seus conceitos de design e sugestões]. Eu vou... ah, eu não sei se eu vou conseguir dormir essa noite. [...] Adorei a marca, adorei a parte que fala sobre essas questões de relações. Acho que eu vou poder juntar tudo isso e fazer uma coisa muito bacana, uma coisa que realmente possa impactar as pessoas. E eu espero inclusive que vocês possam ver isso, e se quiserem participar, colaborar, sabe... vai ser fantástico [...] Isso tá me dando tantas ideias, tantas formas de pensar, tantas formas de repensar, de me repensar, sabe? Que realmente eu vou ter bastante trabalho [...] Obrigada mesmo, muito obrigada mesmo por tudo.

A existência de uma demanda clara para melhorar o bem-estar de alguém, neste caso, trabalhando em interações sociais, tornou o desafio de projeto mais palpável. O uso de forças caráter ao invés de elementos mais genéricos (virtudes) permitiu que os designers relacionassem essas características pessoais a contextos da vida real.

Com inspiração nas experiências educacionais de Demir, Ozkaramanli e Desmet (2010), apresenta-se os aspectos principais propostos e testados nesta abordagem de projeto para o bem-estar, reforçando o uso de forças de caráter, bem como pontos de atenção ao aplicá-los:

- Definir um usuário, ou um grupo de usuários, com uma demanda clara para melhorar o bem-estar subjetivo: isto facilitou as conexões que os designers fizeram entre o briefing do workshop e a realidade da usuária (a), apesar de algumas das discussões terem extrapolado a temática de projeto (b). Designers mostraram propensão a focar na fala da usuária, ao invés de explorarem outras formas de estimular seu bem-estar (i), o que só foi percebido na terceira etapa. É provável que outras formas de acessar informações teriam sido úteis e poderiam ser testadas em outras aplicações deste tipo de proposta em workshops educativos.

- Identificar as forças de caráter mais importantes e relacionar pelo menos uma delas à demanda relatada pelo usuário: esse procedimento facilitou a geração de ideias (c), embora seja comum que os designers confundam seus próprios gatilhos para o bem-estar com as da usuária $(\mathrm{d})$.

- Gerar um perfil de projeto: as observações indicam que neste momento do processo os designers apresentaram dificuldades em relacionar alguns dos elementos do constructo com o briefing proposto, se utilizando apenas dos seguintes elementos: orientação a possibilidades, ajuste pessoal e envolvimento ativo do usuário (e). Sendo assim, a geração de ideias começou sem que os designers soubessem como os outros aspectos do constructo seriam contemplados no projeto; as ideias propostas foram o ponto de partida para que se pensasse nas questões de equilíbrio e impacto de longo prazo (f) e também como uma forma de validação para continuar trabalhando com forças de caráter específicas (g). Portanto, o processo de discutir a teoria e aplicá-la ao processo de projeto não foi linear $(\mathrm{h})$, e seu caráter abstrato criou dificuldades na entrega de soluções de projeto concretas antes da validação (j) usando todos os elementos teóricos $(k)$. Os designers tinham propensão a tentar usar o bem-estar como uma área de aplicação, ao invés de uma área de conhecimento. Em futuras iniciativas, pode ser útil tentar explorar de forma mais profunda que o design para o bem-estar não se limita a projetar produtos ou serviços; ele é uma área de conhecimento (1). Antes de passar para a próxima etapa, a participação da usuária e a 
validação das ideias fornecidas por ela ajudaram a garantir a adequação pessoal dos perfis do projeto $(\mathrm{m})$.

- Projetar o artefato de acordo com o perfil de projeto: a validação do conceito de design com a usuária facilitou a definição de elementos que ainda estavam abertos naquele momento do processo (n), bem como a definição de algumas forças de caráter nas quais o projeto deveria realmente se focar (o).

- Avaliar o potencial da solução proposta para estimular o bem-estar subjetivo - perspectiva do usuário e 6 . Avaliar o projeto de acordo com o constructo e a abordagem do Positive Design: designers foram bem sucedidos em aplicar os três pilares do Positive Design (virtudes, prazer e significado pessoal) (p) e seus cinco elementos: orientação a possibilidades, equilíbrio, adequação pessoal, envolvimento ativo do usuário e impacto de longo prazo (q).

Uma observação geral é que a curta duração do workshop resultou em dificuldades para realização de boas representações visuais dos conceitos de design (r). Destacam-se algumas limitações, sendo as principais a temática e a estrutura única do workshop e sua curta duração. Além disso, é importante evidenciar que o design para o bem-estar pode ser fomentado por muitas teorias, abordagens e métodos para além do Positive Design. Finalmente, as dificuldades que foram resumidas nesta seção final também podem ser vistas como pontos de melhoria. Todas essas limitações podem ser consideradas como oportunidades para futuros estudos.

\section{Bibliografia}

Arnould, E. \& Price, L. (1993). "River magic: extraordinary experience and the extended service encounter", em Journal of Consumer Research, 20, 57-66.

Barros, R.; Martín, J. \& Pinto, J. (2010). “Investigação e Prática em Psicologia Positiva”, em Psicologia Ciência e Profissão, 30 (2), 18-327.

Carr, E. (2007). “The expanding vision of positive behavior support”, em Journal of Positive Behavior Interventions, 9(1), 3-14.

Csikszentmihalyi, M. (1997). Finding flow: the psychology of engagement with everyday life. New York: Basic Books - HarperCollins Publishing.

Dahlsgaard, K.; Peterson, C. \& Seligman, M. (2005). "Shared virtue: The convergence of valued human strengths across culture and history", em Review of General Psychology, 9, 203-213.

Demir, E.; Desmet, P. \& Hekkert, P. (2009). "Appraisal patterns of emotions in humanproduct interaction”, em International Journal of Design, 3(2).

Demir, E.; Ozkaramanli, D. \& Desmet, P. (2010). "How to Design for Emotions: Experiences in a Course", em Proceedings of the 7th International Design \& Emotion Conference, 2010, Chicago: Blatantly Blues, 2010. p. 4-7.

Desmet, P. (2002). Designing emotions. Tese de doutorado, Delft University of Techonolgy. 
Desmet, P. (2009). “Special Issue Editorial: Design \& Emotion”, em International Journal of Design, 3(2), 1-6.

Desmet, P. (2015). "Design for mood: Twenty activity-based opportunities to design for mood regulation”, em International Journal of Design, 9(2), 1-19.

Desmet, P. \& Pohlmeyer, A. (2013). "Positive design: An introduction to design for subjective well-being”, em International Journal of Design, 7(3), 5-19.

Jordan, P. (2000). Designing Pleasurable Products. EUA: CRC Press, p.224, 2000.

Norman, D. (2004). Emotional Design: Why We Love (or Hate) Everyday Things. New York: Basic Books, 272.

Ozkaramanli, D. \& Desmet, P. (2012). “I Knew I Shouldn’t, Yet I Did It Again! Emotiondriven Design as a Means to Motivate Subjective Well-being Interaction", em International Journal of Design, 6(1), 27-39.

Park, N. \& Peterson, C. (2009). "Character Strengths: Research and Practice", em Journal of College and Character, 10(4).

Peterson, C. \& Seligman, M. (2004). Character Strengths and Virtues: A Handbook and Classification. Washington, DC: American Psychological Association.

Sääksjärvi, M. \& Hellén, K. (2013). "How designers and marketers can work together to support consumers' happiness”, em International Journal of Design, 7(3), 33-44.

Seligman, M. \& Csikszentmihalyi, M. (2000). "Positive psychology: An introduction”, em American Psychologist, 55(1), 5-14.

Seligman, M. \& Csikszentmihalyi, M. (2001). "Reply to comments", em American Psychologist, 56(1), 89-90.

Seligman, M.; Steen, T.; Park, N. \& Peterson, C. (2005). "Positive psychology: Empirical validation of interventions", em American Psychologist, 60(5), 410-421.

Sheldon, K. \& King, L. (2001). "Why positive psychology is necessary", em American Psychologist, 56(3), 216-217.

Tonetto, L. \& Costa, F. (2011). "Design Emocional: conceitos, abordagens e perspectivas de pesquisa”, em trategic Design Research Journal, 4(3), 132-140.

Resumen: Las fuerzas de carácter son rasgos personales que indican cómo las personas tratan con adversidades. Cuando aplican esas fuerzas en el cotidiano, su bienestar tiende a ser desarrollado, lo que puede ser estimulado a través del Diseño, según un área emergente denominada Positive Design. Este artículo tiene como objetivo investigar los desafíos encontrados al proyectar para estimular fuerzas de carácter. Siete profesionales graduados, todos los estudiantes de maestría en Diseño fueron preparados para desarrollar proyectos en el área. La investigación se basó en la observación de la práctica de estos diseñadores durante sus actuaciones en talleres de diseño, que tuvieron una temática social como estímulo. En esas ocasiones, una mujer transgénera actuó como usuaria del proyecto y apuntó oportunidades para el desarrollo de su bienestar. Las actividades fueron registradas en video y acompañadas por dos observadores. Los resultados indican que los proyectos 
desarrollados fueron adecuados para estimular el bienestar de la usuaria y discuten los desafíos encontrados durante el proyecto.

Palabras clave: diseño positivo - bienestar humano - filosofía del diseño.

Abstract: Character strengths are personal traits that indicate how individuals handle adversities. When users apply their strengths in everyday life, their wellbeing tends to increase, which can be stimulated by Design, according to an emerging field defined as Positive Design. This paper aims to investigate challenges faced when designing to stimulate character strengths. Seven graduated professionals, who were also master students, were prepared to design in this field. The research was based on the observation of the designers during the workshops, which had a social issue as stimulus. In these situations, a transgender woman played the role of a user and reported opportunities to increase her wellbeing. The activities were registered in video and observed by three researchers. Results indicate that the projects developed during the workshop were adequate to stimulate the user's wellbeing and discuss the challenges encountered during the project development.

Keywords: Positive design - human bienestar - filosofía del diseño.

[Las traducciones de los abstracts fueron supervisadas por el autor de cada artículo] 